\title{
Investigating the Effectiveness of a Dynamic Integrated Approach to Teacher Professional Development
}

\author{
Panayiotis Antoniou ${ }^{* 1}$, Leonidas Kyriakides ${ }^{2}$ \\ and Bert Creemers ${ }^{3}$
}

$\approx$ This paper argues that research on teacher professional development could be integrated with validated theoretical models of educational effectiveness research (EER). A dynamic integrated approach (DIA) to teacher professional development is proposed. The methods and results of a study comparing the impact of the DIA and the Holistic - Reflective Approach (HA) to teacher professional development are presented. Teaching skills and teacher perceptions of teaching of 130 teachers and the achievement of their students $(n=2356)$ were measured at the beginning and at the end of the intervention. Teachers found to be at a certain developmental stage were randomly allocated evenly into two groups. The first group employed the DIA and the second the HA. Teachers employing the DIA managed to improve their teaching skills more than teachers employing the HA. Teacher perceptions and attitudes towards teaching have not been modified due to their participation in the interventions. On the other hand, the use of DIA also had a significant impact on student achievement. Implications of findings for the use of EER for improvement purposes are drawn and suggestions for research and practice in teacher professional development are provided.

Keywords: Dynamic integrated approach, Educational effectiveness research stages of teaching skills, Evaluation of teacher improvement, Teacher professional development

$1 \quad{ }^{\star}$ Corresponding author. Cyprus International Institute of Management (CIIM),

21 Academias Avenue, 2107, Nicosia, Cyprus

pantoniou@ciim.ac.cy

2 University of Cyprus, Department of Education, Cyprus

3 University of Groningen, Faculty of Psychology, Education and Sociology, The Netherlands 


\section{Introduction}

This research is in line with the current approaches of merging the findings of Educational Effectiveness Research (EER) with initiatives to improve education and particularly teacher effectiveness. Many researchers (e.g., Creemers \& Reezigt, 1997; Reynolds, Hopkins \& Stoll, 1993) have identified that an important constraint of the existing approaches of modelling educational effectiveness is the fact that the whole process does not contribute significantly to the improvement of teaching practice. Taking this into consideration, this study aims to contribute to further development of the framework related to the use of the dynamic model of EER (Kyriakides \& Creemers, 2008) for improvement purposes.

Teacher professional development is considered an essential mechanism for deepening teachers' content knowledge and developing their teaching practices in order to teach to high standards (Borko, 2004; Day, 1999). Despite the number of studies on teacher professional development (e.g., Cohen, 1990; Desimone et al., 2002; U. S. Department of Education, 1999) the majority of these studies do not measure the impact of different approaches and programmes on student learning outcomes (Cochran-Smyth \& Zeichner, 2005). While those responsible for professional development have generally assumed a strong and direct relationship between professional development and improvements in student learning, few have been able to describe the precise nature of this relationship (Guskey \& Sparks, 2002). On the other hand, EER addresses questions as to what works in education and why, and refers to specific factors concerned with quality of teaching associated with student achievement.

In this context, the present paper argues that research on teacher professional development should draw from validated theoretical models of EER in order to develop teacher professional development programmes that will not only have an impact on improving teacher knowledge and skills but will ultimately raise educational standards. By establishing links between EER and research on teacher professional development, both fields could enjoy mutual benefits. In particular, research on teacher professional development could expand its research agenda by taking into consideration the impact of effective programmes on student outcomes, while at the same time EER could identify the extent to which its validated theoretical models can be used for improvement purposes. In this way, stronger links between research, policy and improvement of teaching practice could be established. 
This paper presents the results of an experimental study comparing the impact of different approaches to teacher professional development upon the development of: a) teaching skills, b) teacher perceptions of teaching and c) student achievement gains in mathematics. Specifically, the holistic approach (based on teacher reflection), which is considered to be the dominant approach to teacher professional development, and the dynamic integrated approach (based on the groupings of teacher factors of the dynamic model). The methodology of the group-randomisation study, the results and the implications for the development of research and policy on teacher professional development are presented in the following sections.

\section{The Holistic / Reflective Approach}

The dominant approach in teacher professional development is focused on encouraging reflection on teaching practices, experiences, and beliefs (Golby \& Viant, 2007). As Charlene (2008) argues, motivated by the need to prepare their citizens for a knowledge-based economy, many governments are striving to improve their schools by encouraging reflection among teachers. According to Elliot (2002), the expertise of teachers and the extent to which they can improve relates to their ability to continuously question and interrogate the terms and conditions that govern their own transactions with students. In this perspective, Van Manen (2002) proposes three levels of reflectivity: technical reflection, practical reflection and critical reflection. Technical reflection is concerned with techniques and strategies for specific goals, while critical reflection examines broader ethical issues. Situated between these two types of reflection is practical reflection, which goes beyond looking at skills, strategies and rules to question the goals themselves. Emphasis is also given to approaches involving the reflective capabilities of observation, analysis, interpretation and decision-making (Schon, 1983; Zeichner, 1987), which enable teachers to critically review their teaching practice. In addition, this approach involves making use of readings of journal writings, observation notes, transcribed conversations, videotaped analyses and self-regulation (Cornford, 2002).

Although reflection has been very fashionable in all sectors of teacher education for a number of years, there is little solid empirical evidence that supports the view that it results in an improvement of teaching practices (Cornford, 2002; McNamara, 1990). One would 
have anticipated that there would have been concerted efforts to evaluate the practical effectiveness of these various approaches to reflection by empirical methods, but this has not occurred to any appreciable degree (Cochran-Smyth \& Zeichner, 2005).

The results from the few published empirical studies that have attempted to quantify the effects of reflective thinking programmes on teacher thought and classroom performance are rather disappointing (Winitzky \& Arends, 1991). Chandler et al. (1991) found reflection not to be significantly related to teaching performance. In addition, Wubbels and Korthagen (1990), comparing teachers who had graduated recently and some time before from conventional colleges and colleges implementing reflective teaching programmes found no differences between the two groups in attitude to reflection and inclination towards innovation. While there is some evidence that the reflective approach in some studies can produce greater ability to verbalise (Stoiber, 1991), there is no clear evidence that this can be carried through to superior practical teaching performance.

Finally, defining what actually constitutes reflective practices is fraught with difficulty (see Hatton \& Smith, 1995; Tom, 1985). According to Cornford (2002), the ideals or purposes of reflection in education are as manifold as the term itself: development of self-monitoring teachers, teachers as experimenters, teachers as researchers and teachers as inquirers. The above terms associated with reflective teaching have varied both in terms of their conception of the nature of reflective activity and of the content on which teachers are expected to reflect (Calderhead, 1989).

Due to this, it is not always clear exactly what teachers are supposed to reflect on when trying to become better teachers, which is why the main critique of the reflective paradigm is that reflective approaches lack a grounded theoretical base on which specific teaching skills could be developed. Taking this into consideration, the present paper argues that EER, and especially the dynamic model of educational effectiveness (Creemers \& Kyriakides, 2008), could be used for developing an integrated approach to teacher professional development.

\section{The Dynamic Integrated Approach}

The dynamic model of educational effectiveness was developed in order to establish links between EER and improvement practices (Creemers \& Kyriakides, 2006). In relation to the teacher level, the 
dynamic model refers to eight factors that describe teachers' instructional role and are associated with student outcomes: orientation, structuring, questioning, teaching-modelling, applications, management of time, teacher role in making the classroom a learning environment, and classroom assessment. These eight factors do not refer only to one approach of teaching, such as the direct teaching model or the new teaching approach. An integrated approach in defining quality of teaching is adopted.

The dynamic model is also based on the assumption that although there are different effectiveness factors, each factor can be defined and measured using five dimensions: frequency, focus, stage, quality and differentiation. Frequency is a quantitative way to measure the functioning of each effectiveness factor, and studies within the process-product paradigm were only concerned with this dimension. The other four dimensions examine qualitative characteristics of the functioning of the factors and help us describe the complex nature of effective teaching (for further information on the conceptual background of the teacher factors of the dynamic model and the five measurement dimensions see Creemers \& Kyriakides, 2008).

Another main assumption of the model is that these factors and their dimensions may be interrelated, and the importance of grouping specific factors for explaining achievement gains has been investigated. In particular, a longitudinal study revealed that the teacher factors of the dynamic model can be grouped into five levels, which are situated in developmental order (Kyriakides, Creemers \& Antoniou, 2009). Table 1 demonstrates how the 42 teaching skills emerging from the dynamic model are grouped into these five stages. 
Table 1. The five developmental stages of teaching skills included in the Dynamic Model

\begin{tabular}{|c|c|}
\hline STAGES & TEACHING SKILLS \\
\hline $\begin{array}{l}\mathbf{1} \\
\text { Basic elements of direct teaching }\end{array}$ & $\begin{array}{ll}\text { - } & \text { Frequency management time } \\
\text { - } & \text { Stage management of time } \\
- & \text { Frequency structuring } \\
- & \text { Frequency application } \\
- & \text { Frequency assessment } \\
- & \text { Frequency questioning } \\
- & \text { Frequency teacher-student relation }\end{array}$ \\
\hline $\begin{array}{l}2 \\
\text { Putting aspects of quality } \\
\text { in direct teaching and touching } \\
\text { on active teaching }\end{array}$ & $\begin{array}{ll} & \text { Stage structuring } \\
\text { - } & \text { Quality application } \\
\text { - } & \text { Stage questioning } \\
- & \text { Frequency student relations } \\
- & \text { Focus application } \\
- & \text { Stage application } \\
- & \text { Quality of questions }\end{array}$ \\
\hline $\begin{array}{l}3 \\
\text { Acquiring quality } \\
\text { in active/direct teaching }\end{array}$ & 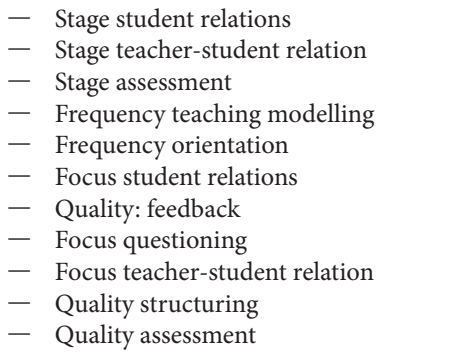 \\
\hline $\begin{array}{l}4 \\
\text { Differentiation of teaching }\end{array}$ & $\begin{array}{l}\text { - Differentiation structuring } \\
- \text { Differentiation time management } \\
- \text { Differentiation questioning } \\
-\quad \text { Differentiation application } \\
-\quad \text { Focus assessment } \\
-\quad \text { Differentiation assessment } \\
-\quad \text { Stage teaching modelling } \\
-\quad \text { Stage orientation }\end{array}$ \\
\hline $\begin{array}{l}\mathbf{5} \\
\text { Achieving quality } \\
\text { and differentiation in teaching } \\
\text { using different approaches }\end{array}$ & $\begin{array}{ll}\text { - } & \text { Quality teacher-student relation } \\
- & \text { Quality student relations } \\
- & \text { Differentiation teacher-student relation } \\
- & \text { Differentiation student relations } \\
- & \text { Focus orientation } \\
- & \text { Quality orientation } \\
- & \text { Differentiation orientation } \\
- & \text { Quality of teaching modelling } \\
- & \text { Focus teaching modelling }\end{array}$ \\
\hline
\end{tabular}

Looking at the description of these five levels in terms of the teaching skills situated in each level, one can observe that the first three levels are mainly related to the direct and active teaching approach by moving from the basic requirements concerning quantitative characteristics of teaching routines to the more advanced requirements concerning the appropriate use of these skills as measured by the qualitative 
characteristics of these factors. These skills also gradually move from the use of teacher-centred approaches to the active involvement of students in teaching and learning. The last two levels are more demanding since teachers are expected to differentiate their instruction (level 4) and also to demonstrate their ability to use the new teaching approach. Furthermore, taking student outcomes as criteria, teachers who demonstrate competencies in relation to higher levels were found to be more effective than those situated at the lower levels. This association is found for achievement in different subjects and for both cognitive and affective outcomes (Kyriakides, Creemers, Antoniou, 2009).

Specific strategies for improving effectiveness that are more comprehensive in nature may emerge by looking at the grouping of teacher factors of the dynamic model. In this context, Creemers, Kyriakides and Antoniou (in press) develop the DIA to teacher professional development. It is argued that teacher professional development should be focused on how to address specific groupings of teacher factors associated with student learning rather than with an isolated teaching factor or with the whole range of teacher factors (as implied by the Reflective Approach) without considering the professional needs of student teachers and teachers. Each grouping of factors refers to different developmental stages of teacher professional behaviour and the dimensions used to measure their functioning may help us develop programmes assisting teachers to improve their teaching skills by moving from easier to more complicate stages.

The dynamic dimension of this approach is attributed to the fact that its content derives from the grouping of teaching skills included in the dynamic model, while at the same time it is differentiated to meet the specific needs and priorities of teachers who were found to be situated in each developmental stage. Similarly, the integrated dimension of this approach is attributed to the fact that although its content refers to teaching skills that were found to be positively related to student achievement (drawn from EER) the participants are also engaged in systematic critical reflection upon these teaching skills (drawn from their experiences and perceptions).

\section{Methods}

A group randomisation study was conducted in order to compare the impact of the HA and the DIA approaches. Information about the participants, the four phases of the study and the research measures is provided below. 


\section{Participants}

A total number of 130 teachers volunteered to participate in the professional development programme. Although the sample was not randomly selected, it was representative of the teacher population of Cyprus in terms of gender $\left(\chi^{2}=0.84\right.$, d.f. $\left.=1, p=0.42\right)$ and years of experience $(\mathrm{t}=1.21$, d.f. $=1835, \mathrm{p}=0.22)$. Data were also collected from all students $(n=2356)$ of the teacher sample. The student sample was representative of the elementary school student population of Cyprus in terms of gender $\left(\chi^{2}=0.89\right.$, d.f. $\left.=1, p=0.43\right)$.

Data were collected both at the beginning and at the end of the intervention. Students with missing prior attainment or background data represented less than $7 \%$ of the original sample and were therefore excluded from each analysis. In regard to the teacher sample, only seven teachers left the experimental study. These teachers were equally distributed through the two intervention groups and the stage at which they were found to belong.

\section{Phases of the study}

The four phases of the experimental study are elaborated below.

\section{Phase 1: Initial evaluation}

At the beginning of the 2008-2009 school year, the teaching skills of the participants were evaluated by external observers. Data on student achievement were collected using external written forms of assessment designed to assess knowledge and skills in mathematics as identified in the Cyprus Curriculum (Ministry of Education, 1994). Teacher questionnaires were administered in order to collect data on teacher background characteristics and measure their perceptions of teaching. In addition, a student questionnaire was administered in order to collect information related to student background characteristics. Observation data were then analysed using the same procedure as described by Kyriakides et al. (2009) in order to classify teachers into developmental stages according to their teaching skills. Using the Rasch and the Saltus models, it was found that teachers could be classified into the same five developmental stages that had emerged from the previous study (see table 1).

\section{Phase 2: The formation of the two experimental groups}

The teachers who were found to be at a certain developmental stage were randomly allocated into two teams of equal size. The first 
team employed the DIA and the second the HA. For example, the 32 teachers who proved to be at Stage 1 were randomly allocated into two experimental groups, each consisting of 16 teachers.

\section{Phase 3: Establishment of training sessions}

In this phase, the teachers of each experimental group had to attend nine sessions, as described below:

i) First Session

The first session was a common/introductory session for all of the teachers of our sample and took place before the initial evaluation (phase 1). In this session the main phases of the professional development programme were analysed. The importance of evaluating the impact of this professional development programme was stressed. It was made clear that provisions had been taken to ensure the anonymity and confidentiality of the evaluation results. Finally, training on how to develop an action plan was provided.

ii) Sessions for teachers employing the DIA

At the second session, the teachers employing the DIA were assigned to four groups according to their development stage. Supporting literature and material related to the teaching skills corresponding to their developmental stage were provided and the area on which each group had to concentrate their efforts for improvement was made clear. Finally, each teacher developed his/her action plan by exchanging ideas with the research team and the members of his/her group.

After the second session, one session per month was scheduled until the end of the school year. This decision provided the teachers with sufficient time to implement the activities included in their action plans and also to reflect on the effectiveness of these activities in order to revise and improve their action plans. The monthly sessions were organised in groups (based on teachers' stages) and teachers were strongly encouraged to cooperate and share ideas and teaching materials, to exchange and discuss their experiences and generally to share the results of their exploration. Teachers' training was based on "active teaching" and the participating teachers had an opportunity to report teaching practices and comment on them, to identify effective and non-effective teaching practices, and to identify the significance of the effectiveness factors corresponding to their developmental stage and how these factors could be linked with effective teaching. Finally, researchers regularly visited teachers at their schools to discuss emerging issues and to provide them with support and feedback. 
iii) Sessions for teachers employing the HA

The primary aim of these sessions was to enable individuals to critically evaluate their own beliefs and practice and help them to transform their experiences from a past event to an ongoing learning process. In the second session, teachers had an opportunity to undertake discussion in groups, identify a problem that they considered important in their teaching and formulate a plan of action to tackle this problem. After the second session and the development of the teachers' initial action plans we scheduled one session per month until the end of the school year. This decision provided the teachers with sufficient time to implement the activities included in their action plans and to reflect on the effectiveness of these activities.

The monthly sessions provided the teachers of each stage with an opportunity to revise and further develop their action plans, based on their own and others' experiences. The participating teachers had an opportunity to report their teaching practices and comment on them, and to identify effective and non-effective teaching practices, attitudes and beliefs. For example, the teachers were asked to reflect on what they perceived to be successes and failures in terms of effective teaching and learning. Then they were encouraged to focus on one critical incident (positive or negative) that occurred in their classrooms and to write down their story of experience. They had to describe the incident in detail (e.g., situation, people involved, feelings and reasoning), what they had learned about teaching as a result, how their perspectives had changed and the changes they had made in how they taught as a result. At each monthly meeting we encouraged the teachers within the same group to cooperate and share ideas and teaching materials, and to exchange and discuss their experiences. Finally, as with the teachers employing the DIA, during that period the research team visited the teachers at their schools to discuss emerging issues related to the implementation of their action plans in their everyday teaching.

\section{Phase 4: Final evaluation}

By the end of the school year, the teaching skills, teacher perceptions of teaching and student achievement were measured using the same procedure as in Phase 1 of the study. Then a final meeting with all of the teachers took place in order to get feedback about the programme and present the results of the study. 


\section{Measures}

\section{Student achievement in mathematics}

For each year group of students, criterion-reference tests in mathematics were constructed in order to measure their knowledge and skills in mathematics in relation to the objectives of the national curriculum in Cyprus. The tests for different age groups were equated using IRT modelling in order to make the comparison of the test scores meaningful (see Antoniou, 2009).

\section{Student background factors}

Information was collected on two student background factors: sex (o=boys, $1=$ girls), and socioeconomic status (SES). Five SES variables were available: father's and mother's education level, the social status of the father's job, the social status of the mother's job and the economic situation of the family. Following the classification of occupations used by the Ministry of Finance, it was possible to classify parents' occupations into three groups with relatively similar sizes: occupations held by the working class $(32 \%)$, occupations held by the middle class (39\%) and occupations held by the upper-middle class (29\%). Standardised values of the above five variables were calculated, resulting in the SES indicator.

\section{Opportunity to learn}

Time spent doing homework and time spent on private tuition were seen as measures of the opportunity to learn factor. Private tuition in Cyprus is common and a high percentage of students attend private lessons. Thus students were asked to report the average amount of time spent on homework and on private tuition in mathematics.

\section{Contextual factors at teacher/classroom level}

Variables concerned with the context of each classroom, such as the average score at the beginning of the intervention, the average SES score and the percentage of girls, were taken into account. The contextual factors were aggregated from the student level data. We were also able to collect data about three teacher background variables: gender, position (i.e. teacher or deputy head) and teaching experience.

\section{Teacher background characteristics}

Information related to teacher gender (male/female), position 
(teacher/deputy head) and years of experience was collected. In addition, teachers were asked to indicate their future expectations (to do a postgraduate degree, to be promoted, etc.) and finally to indicate their attitudes towards teaching as a profession on a Likert scale ranging from 1 (most negative) to 7 (most positive).

\section{Teacher perceptions of the characteristics of effective teachers}

Teachers were also asked to provide information related to their perceptions of the characteristics of effective teachers. Specifically, the teachers had to indicate on a Likert scale ranging from 1 (least significant) to 5 (most significant) how they perceived the significance of several characteristics, such as being patient, having organisational skills, being able to communicate effectively with children, etc. The reliability of this section was calculated and the value of Cronbach Alpha for each subscale was found to be satisfactory, ranging from 0.75 to 0.84 .

Then, in order to examine the construct validity of this part of the questionnaire, a first-order Confirmatory Factor Analysis (CFA) model, designed to test the multidimensionality of a theoretical construct (Byrne, 1998), was used. Specifically, the model hypothesised that: (a) the 4 sub-scale scores could be explained by one factor; (b) each sub-scale would have a nonzero loading on this factor; and (c) measurement errors would be uncorrelated. The findings of the first order factor SEM analysis generally affirmed the theory on which this section of the questionnaire was developed. Specifically, the scaled $\chi^{2}$ for the one factor structure $\left(\chi^{2}=2.3, \mathrm{df}=2, \mathrm{p} .31\right)$ did not reach statistical significance, the RMSEA was .013 and the CFI was .966, all meeting the criteria for an acceptable level of fit. All parameter estimates were statistically significant $(\mathrm{p}<.001)$. Validation of the first-order factor structure related to this variable provided support for the use of a single score concerned with perceptions of the characteristics of effective teachers.

\section{Teacher attitudes towards tasks that teachers have to perform}

A Likert scale was used in which teachers had to indicate the degree to which they like performing several tasks by indicating a number from 1 (least significant) to 5 (most significant). For example, teachers were asked to demonstrate their attitudes towards lesson preparation, dealing with discipline problems, assessing students' performance, etc. In order to examine the construct validity of this part 
of the questionnaire, a first-order CFA model was used. Specifically, the model hypothesised that: (a) the six sub-scales scores could be explained by two factors (i.e., Direct effect on learning and Indirect effect on learning); (b) each item (i.e., sub-scale score) would have a nonzero loading on the factor it was designed to measure and zero loadings on the other factor; (c) the two factors would be uncorrelated, and (d) measurement errors would be uncorrelated. The findings of the first order factor SEM analysis generally affirmed the theory upon which this section of the questionnaire was developed. The scaled $\chi^{2}$ for the two factor structure $\left(\chi^{2}=7.78, \mathrm{df}=5, \mathrm{p}=.17\right)$ was not statistically significant, the RMSEA was .073 and the CFI was .972, all meeting the criteria for an acceptable level of fit. Thus a decision was made to consider the two-factor structure as reasonable and the parameter estimates were calculated.

\section{Quality of teaching}

Quality of teaching was measured through classroom observations by independent observers both at the beginning (September 2008) and at the end (May 2009) of the intervention. Two low-inference instruments and one high-inference observation instrument were used. The instruments were designed to collect data concerning the teacher factors of the dynamic model, and their construct validity had already been tested using Structural Equation Modelling approaches (see Kyriakides \& Creemers, 2008).

Observations were carried out by three members of the research team, all of whom had attended a series of seminars on how to use the three instruments. During the 2008-2009 school year, the external observers visited each class four times. For each scale of the instruments the alpha reliability coefficient was higher than 0.83 . Since $26 \%$ of the lessons were observed by pairs of observers, the inter-rater reliability coefficient ( $\left.\rho_{2}\right)$ was estimated and was found to be higher than 0.81 .

\section{Implementation effort}

Since one of the main threats to the internal validity of experimental studies has to do with the extent to which all of the groups put the same effort into implementing the intervention, different sources of data were used to measure this variable. Specifically, we conducted content analysis of the reflective diaries that each teacher kept in order to identify the extent to which the members of each group put effort into implementing their action plans in their teaching. Moreover, 
the constant comparative method was used to analyse data emerging from interviews with each teacher participating in this study. These interviews were concerned with the experiences, the attitudes and the amount of time each teacher devoted to the implementation of the intervention. The analysis of the qualitative data from each source of data helped us generate ordinal data measuring the extent to which teachers of each experimental group put effort into implementing their improvement strategies and action plans. The Kolmogorov-Smirnov two sample test did not reveal statistically significant differences between the members of the two experimental groups in terms of their implementation effort $(\mathrm{K}-\mathrm{S} \mathrm{Z}=1.01, \mathrm{p}=0.36)$.

\section{Results}

\section{Impact on teaching skills}

The observational data of each period were analysed separately following the procedure described by Kyriakides et al. (2009). Specifically, the Rasch model was used in order to identify the extent to which the five dimensions of the eight teacher factors (i.e., the 44 first order factor scores) could be reducible to a common unidimensional scale. The Rasch model does not test only the unidimensionality of the scale but also is able to determine whether the tasks can be ordered according to the degree of their difficulty and whether at the same time the people who carry out these tasks can be ordered according to their performance in the construct under investigation. When the Rasch model was applied to the data of the baseline measure it was found that all of the teaching skills included in the dynamic model were well targeted against the persons' measures, since Rasch person estimates range from -3.06 to 3.12 logits and the estimates of the difficulties of teaching skills ranged from -2.93 to 3.16 logits. Moreover, the reliability of persons (i.e., teachers) and items (i.e., teaching skills) is calculated through the Rasch analysis, indicating how well the scale discriminates among teachers based on their estimated teaching skills and how well the teaching skills can be discriminated from one another on the basis of their difficulty. It was found that the separability of each scale is satisfactory (i.e., higher than o.93). This implies that the reliability of the scale is very high and furthermore indicates that five levels could be discerned (Bond \& Fox, 2001). Finally, the fitting of the Rasch model to the data was tested against alternative item response theory models and was found to be statistically preferable.

Having established the reliability of the scale, it was investigated 
whether teaching skills could be grouped into the five stages described in the previous section. The procedure for detecting pattern clustering developed by Marcoulides and Drezner (1999) was used. This procedure enables us to segment the observed measurements into constituent groups (or clusters) so that the members of any one group are similar to one another, according to a selected criterion that stands for difficulty. Applying this method to segment the teaching skills on the basis of the difficulties that emerged from the Rasch model showed that they are optimally clustered into the five clusters proposed by previous research findings. The cumulative $\mathrm{D}$ for the five-cluster solution was $58 \%$, whereas the sixth gap adds only $4 \%$.

The above procedure was also employed to analyse data that emerged from the final measurement of teaching skills. The Rasch model revealed that there was no person who did not fit the model, and that all of the teaching skills were well targeted against the persons' measures since persons' scores range from -2.99 to 3.24 logits. It was also found that the difficulties of the teaching skills could be considered invariant across the two measurement periods within the measurement error (i.e., o.10 logits). Furthermore, the indices of persons and of teaching skills separation were found to be higher than 0.94, indicating that the separability of each scale is satisfactory. Applying the clustering method mentioned above, it was found that the teaching skills could again be optimally clustered into five clusters.

By comparing the classification of teachers into different stages at the beginning and at the end of the intervention, it was found that none of the teachers of the group employing the HA managed to move from one stage to another. On the other hand, 21 of the 65 teachers employing the DIA managed to move to the next stage, whereas the other teachers remained at the same stage. Specifically, 8 teachers of this group moved from stage one to stage two, 8 teachers of stage two managed to move to stage three and 5 teachers of stage three were found to be situated at stage four at the end of the intervention.

In order to measure the impact of the two professional development programmes on teaching skills we also compared the Rasch person estimates. This comparison reveals that the final score of teachers employing the DIA (Mean=0.36, $\mathrm{SD}=1.05$ ) was higher than their initial score (Mean=-0.28, $\mathrm{SD}=1.01)$, and that this difference was statistically significant $(\mathrm{t}=4.14, \mathrm{df}=64, \mathrm{p}<.001)$. On the other hand, the final score of teachers employing the HA (Mean=-0.25, SD=1.04) was not higher than their initial score (Mean=-0.26, $\mathrm{SD}=1.05)$ and the $\mathrm{t}$-test for paired 
samples did not reveal any statistically significant progress $(t=0.87$, $\mathrm{df}=64, \mathrm{p}=0.38$ ).

\section{Impact on teacher perceptions and attitudes}

At the first stage of the analysis, an independent sample t-test was employed to identify any statistically significant difference between the teachers of the two experimental groups both at the beginning and at the end of the interventions. No statistically significant differences could be identified between the teachers of the two experimental groups at the beginning of the interventions. Similarly, the independent sample t-test was employed to identify statistically significant differences between the teachers of the two experimental groups at the end of the interventions. Again, no statistically significant differences could be identified. Information about the perceptions of each group before and after the innovation is presented in Appendix 1. Finally, the paired-sample t-test revealed that no statistically significant changes in perceptions could be identified either for the teachers who employed the DIA or for those who employed the HA.

\section{Impact on student achievement}

The results of the multilevel analysis conducted in order to measure the impact of each of the two approaches to teacher professional development on student achievement are presented in this part. Empty models with all possible combinations of the levels of analysis (i.e., student, teacher and school) were established and the likelihood statistics of each model were compared (Snijders \& Bosker, 1999). An empty model consisting of student, teacher and school level represented the best solution. The empty model revealed that $72.3 \%$ of the total variance was situated at the student level, $18.5 \%$ of the variance was at the classroom level and $10.2 \%$ was at the school level. In subsequent steps explanatory variables at different levels were added, starting at the student level. Explanatory variables, except grouping variables, were centred as Z-scores with a mean of o and a standard deviation of 1. Grouping variables were entered as dummies with one of the groups as baseline (e.g., girls=o). The models presented in Table 2 were estimated without the variables that did not have a statistically significant effect at level .05. 
Table 2. Parameter estimates (and standard errors) for the analysis of student achievement in mathematics (students within classes, within schools)

\begin{tabular}{|c|c|c|c|c|c|c|c|}
\hline Factors & \begin{tabular}{r|} 
Model \\
0
\end{tabular} & \begin{tabular}{r|} 
Model \\
1 \\
\end{tabular} & $\begin{array}{r}\text { Model } \\
2 \\
\end{array}$ & $\begin{array}{r}\text { Model } \\
3 \\
\end{array}$ & $\begin{array}{r}\text { Model } \\
4 \\
\end{array}$ & $\begin{array}{r}\text { Model } \\
5\end{array}$ & $\begin{array}{r}\text { Model } \\
6\end{array}$ \\
\hline $\begin{array}{l}\text { Fixed part } \\
\text { (Intercept) }\end{array}$ & $\begin{array}{r}5.19 \\
(0.80) \\
\end{array}$ & $\begin{array}{r}4.10 \\
(0.78) \\
\end{array}$ & $\begin{array}{r}3.80 \\
(0.80) \\
\end{array}$ & $\begin{array}{r}3.70 \\
(0.90) \\
\end{array}$ & $\begin{array}{r}2.90 \\
(0.80) \\
\end{array}$ & $\begin{array}{r}2.10 \\
(0.80) \\
\end{array}$ & $\begin{array}{r}1.90 \\
(0.70) \\
\end{array}$ \\
\hline \multicolumn{8}{|l|}{ Student Level } \\
\hline \multicolumn{8}{|l|}{ Context } \\
\hline $\begin{array}{l}\text { Prior } \\
\text { achievement in } \\
\text { maths }\end{array}$ & & $\begin{array}{r}0.80 \\
(.12)\end{array}$ & $\begin{array}{r}0.79 \\
(.12)\end{array}$ & $\begin{array}{l}0.81 \\
(.12)\end{array}$ & $\begin{array}{r}0.80 \\
(.11)\end{array}$ & $\begin{array}{l}0.80 \\
(.12)\end{array}$ & $\begin{array}{r}0.80 \\
(.11)\end{array}$ \\
\hline Grade 3 & & $\begin{array}{r}-1.20 \\
(.40) \\
\end{array}$ & $\begin{array}{r}-1.09 \\
(.40) \\
\end{array}$ & $\begin{array}{r}-1.08 \\
(.40) \\
\end{array}$ & $\begin{array}{r}-1.10 \\
(.40) \\
\end{array}$ & $\begin{array}{r}-1.07 \\
(.40) \\
\end{array}$ & $\begin{array}{r}-1.07 \\
(.40) \\
\end{array}$ \\
\hline Grade 4 & & $\begin{array}{r}-0.72 \\
(.30) \\
\end{array}$ & $\begin{array}{r}-0.66 \\
(.30) \\
\end{array}$ & $\begin{array}{r}-0.62 \\
(.30) \\
\end{array}$ & $\begin{array}{r}-0.63 \\
(.30) \\
\end{array}$ & $\begin{array}{r}-0.62 \\
(.30) \\
\end{array}$ & $\begin{array}{r}-0.62 \\
(.29) \\
\end{array}$ \\
\hline Grade 6 & & $\begin{array}{r}0.65 \\
(.30) \\
\end{array}$ & $\begin{array}{r}0.64 \\
(.30) \\
\end{array}$ & $\begin{array}{r}0.64 \\
(.30) \\
\end{array}$ & $\begin{array}{r}0.65 \\
(.30) \\
\end{array}$ & $\begin{array}{r}0.66 \\
(.30) \\
\end{array}$ & $\begin{array}{r}0.64 \\
(.30) \\
\end{array}$ \\
\hline $\begin{array}{l}\text { Sex }(0=\text { girls, } \\
1=\text { boys })\end{array}$ & & $\begin{array}{r}0.10 \\
(.04) \\
\end{array}$ & $\begin{array}{r}0.10 \\
(.04) \\
\end{array}$ & $\begin{array}{r}0.11 \\
(.04) \\
\end{array}$ & $\begin{array}{r}0.10 \\
(.04) \\
\end{array}$ & $\begin{array}{r}0.09 \\
(.04) \\
\end{array}$ & $\begin{array}{r}0.10 \\
(.04) \\
\end{array}$ \\
\hline SES & & $\begin{array}{r}0.40 \\
(.14) \\
\end{array}$ & $\begin{array}{l}0.41 \\
(.14) \\
\end{array}$ & $\begin{array}{r}0.40 \\
(.14) \\
\end{array}$ & $\begin{array}{r}0.41 \\
(.14) \\
\end{array}$ & $\begin{array}{r}0.40 \\
(.14) \\
\end{array}$ & $\begin{array}{r}0.40 \\
(.13) \\
\end{array}$ \\
\hline Cultural Capital & & $\begin{array}{r}0.19 \\
(.08) \\
\end{array}$ & $\begin{array}{r}0.19 \\
(.09) \\
\end{array}$ & $\begin{array}{r}0.20 \\
(.08) \\
\end{array}$ & $\begin{array}{r}0.18 \\
(.08) \\
\end{array}$ & $\begin{array}{r}0.18 \\
(.08) \\
\end{array}$ & $\begin{array}{r}0.18 \\
(.08) \\
\end{array}$ \\
\hline \multicolumn{8}{|c|}{ Opportunity to learn } \\
\hline Homework & & & $\begin{array}{r}0.12 \\
(.04) \\
\end{array}$ & $\begin{array}{r}0.12 \\
(.04) \\
\end{array}$ & $\begin{array}{r}0.12 \\
(.04) \\
\end{array}$ & $\begin{array}{r}0.12 \\
(.04) \\
\end{array}$ & $\begin{array}{l}0.12 \\
(.04) \\
\end{array}$ \\
\hline $\begin{array}{l}\text { Private tuition } \\
(0=\text { no, } 1=\text { yes })\end{array}$ & & & N.S.S. & N.S.S. & N.S.S. & N.S.S. & N.S.S. \\
\hline \multicolumn{8}{|l|}{ Classroom Level } \\
\hline \multicolumn{8}{|l|}{ Context } \\
\hline $\begin{array}{l}\text { Average } \\
\text { achievement in } \\
\text { maths }\end{array}$ & & $\begin{array}{r}0.40 \\
(.10)\end{array}$ & $\begin{array}{r}0.40 \\
(.10)\end{array}$ & $\begin{array}{r}0.40 \\
(.10)\end{array}$ & $\begin{array}{r}0.40 \\
(.10)\end{array}$ & $\begin{array}{r}0.40 \\
(.10)\end{array}$ & $\begin{array}{r}0.40 \\
(.10)\end{array}$ \\
\hline Average SES & & N.S.S. & N.S.S. & N.S.S. & N.S.S. & N.S.S. & N.S.S. \\
\hline $\begin{array}{l}\text { Average cultural } \\
\text { capital }\end{array}$ & & N.S.S. & N.S.S. & N.S.S. & N.S.S. & N.S.S. & N.S.S. \\
\hline $\begin{array}{l}\text { Percentage of } \\
\text { girls }\end{array}$ & & N.S.S. & N.S.S. & N.S.S. & N.S.S. & N.S.S. & N.S.S. \\
\hline \multicolumn{8}{|c|}{ Teacher background } \\
\hline $\begin{array}{l}\text { Gender }(0=\text { male, } \\
1=\text { female })\end{array}$ & & & & N.S.S. & N.S.S. & N.S.S. & N.S.S. \\
\hline $\begin{array}{l}\text { Years of } \\
\text { experience }\end{array}$ & & & & $\begin{array}{r}0.08 \\
(.03) \\
\end{array}$ & N.S.S. & N.S.S. & N.S.S. \\
\hline Position & & & & N.S.S. & N.S.S. & N.S.S. & N.S.S. \\
\hline
\end{tabular}




\begin{tabular}{|c|c|c|c|c|}
\hline \multicolumn{5}{|c|}{ Teacher expectations } \\
\hline $\begin{array}{l}\text { Plans for } \\
\text { postgraduate } \\
\text { degree }\end{array}$ & N.S.S. & N.S.S. & N.S.S. & N.S.S. \\
\hline $\begin{array}{l}\text { Plans for } \\
\text { promotion to } \\
\text { head }\end{array}$ & N.S.S. & N.S.S. & N.S.S. & N.S.S. \\
\hline $\begin{array}{l}\text { Attitudes } \\
\text { towards teaching } \\
\text { as a profession }\end{array}$ & N.S.S. & N.S.S. & N.S.S. & N.S.S. \\
\hline \multicolumn{5}{|c|}{ Perceptions of characteristics of effective teachers } \\
\hline $\begin{array}{l}\text { A) Importance of } \\
\text { knowledge }\end{array}$ & N.S.S. & N.S.S. & N.S.S. & N.S.S. \\
\hline $\begin{array}{l}\text { B) Classroom } \\
\text { management }\end{array}$ & N.S.S. & N.S.S. & N.S.S. & N.S.S. \\
\hline C) Personal traits & N.S.S. & N.S.S. & N.S.S. & N.S.S. \\
\hline $\begin{array}{l}\text { D) } \\
\text { Communication } \\
\text { skills }\end{array}$ & N.S.S. & N.S.S. & N.S.S. & N.S.S. \\
\hline \multicolumn{5}{|c|}{ Attitudes towards tasks that teachers have to undertake } \\
\hline $\begin{array}{l}\text { A) Lesson } \\
\text { preparation }\end{array}$ & N.S.S. & N.S.S. & N.S.S. & N.S.S. \\
\hline B) Teaching & N.S.S. & N.S.S. & N.S.S. & N.S.S. \\
\hline C) Assessment & N.S.S. & N.S.S. & N.S.S. & N.S.S. \\
\hline $\begin{array}{l}\text { D) Homework } \\
\text { assignment }\end{array}$ & N.S.S. & N.S.S. & N.S.S. & N.S.S. \\
\hline $\begin{array}{l}\text { E) Record } \\
\text { keeping and } \\
\text { reporting } \\
\text { to parents }\end{array}$ & N.S.S. & N.S.S. & N.S.S. & N.S.S. \\
\hline $\begin{array}{l}\text { F) } \\
\text { Administrative } \\
\text { work }\end{array}$ & $\begin{array}{l}-0.06 \\
(.02)\end{array}$ & $\begin{array}{r}-0.05 \\
(.02)\end{array}$ & $\begin{array}{r}-0.06 \\
(.02)\end{array}$ & $\begin{array}{l}-0.06 \\
(.02)\end{array}$ \\
\hline $\begin{array}{l}\text { Attitudes } \\
\text { towards } \\
\text { professional } \\
\text { development }\end{array}$ & N.S.S. & N.S.S. & N.S.S. & N.S.S. \\
\hline \multicolumn{5}{|l|}{ Quality of teaching } \\
\hline Level 1 & & $\begin{array}{r}-0.52 \\
(.09)\end{array}$ & $\begin{array}{r}-0.51 \\
(.09)\end{array}$ & $\begin{array}{r}-0.52 \\
(.09)\end{array}$ \\
\hline Level 2 & & $\begin{array}{c}-0.24 \\
(.09) \\
\end{array}$ & $\begin{array}{r}-0.25 \\
(.09) \\
\end{array}$ & $\begin{array}{l}-0.25 \\
(.09) \\
\end{array}$ \\
\hline Level 4 & & $\begin{array}{l}0.32 \\
(.10)\end{array}$ & $\begin{array}{l}0.32 \\
(.10)\end{array}$ & $\begin{array}{l}0.31 \\
(.10)\end{array}$ \\
\hline $\begin{array}{l}\text { Experimental } \\
\text { group }(0=\text { only } \\
\text { reflection, } \\
1=\text { competence } \\
\text { based })\end{array}$ & & & $\begin{array}{r}0.24 \\
(.08)\end{array}$ & $\begin{array}{l}0.23 \\
(.08)\end{array}$ \\
\hline
\end{tabular}




\begin{tabular}{|c|c|c|c|c|c|c|c|}
\hline $\begin{array}{l}\text { Teachers who } \\
\text { managed to } \\
\text { move to the next } \\
\text { stage } \\
\text { ( } 0=\text { no movement } \\
\text { was observed, } \\
1=\text { move to the } \\
\text { next) }\end{array}$ & & & & & & & $\begin{array}{r}0.09 \\
(.03)\end{array}$ \\
\hline \multicolumn{8}{|l|}{ School Level } \\
\hline \multicolumn{8}{|l|}{ Context } \\
\hline $\begin{array}{l}\text { Average } \\
\text { achievement in } \\
\text { maths }\end{array}$ & & $\begin{array}{r}0.09 \\
(.04)\end{array}$ & $\begin{array}{r}0.10 \\
(.04)\end{array}$ & $\begin{array}{l}0.08 \\
(.04)\end{array}$ & $\begin{array}{r}0.10 \\
(.04)\end{array}$ & $\begin{array}{r}0.09 \\
(.04)\end{array}$ & $\begin{array}{r}0.09 \\
(.03)\end{array}$ \\
\hline Average SES & & N.S.S. & N.S.S. & N.S.S. & N.S.S. & N.S.S. & N.S.S. \\
\hline $\begin{array}{l}\text { Average cultural } \\
\text { capital }\end{array}$ & & N.S.S. & N.S.S. & N.S.S. & N.S.S. & N.S.S. & N.S.S. \\
\hline $\begin{array}{l}\text { Percentage of } \\
\text { girls }\end{array}$ & & N.S.S. & N.S.S, & N.S.S, & N.S.S, & N.S.S, & N.S.S, \\
\hline \multicolumn{8}{|c|}{ Variance components } \\
\hline School & $10.2 \%$ & $10.0 \%$ & $9.8 \%$ & $9.5 \%$ & $9.1 \%$ & $8.5 \%$ & $8.4 \%$ \\
\hline Class & $18.5 \%$ & $17.6 \%$ & $17.2 \%$ & $16.0 \%$ & $11.0 \%$ & $9.0 \%$ & $8.6 \%$ \\
\hline Student & $72.3 \%$ & $49.0 \%$ & $45.0 \%$ & $44.3 \%$ & $44.1 \%$ & $44.0 \%$ & $44.0 \%$ \\
\hline Explained & & $23.4 \%$ & $28.0 \%$ & $30.2 \%$ & $35.8 \%$ & $38.5 \%$ & $39.0 \%$ \\
\hline \multicolumn{8}{|l|}{ Significance test } \\
\hline$x^{2}$ & 1213.4 & 687.3 & 650.1 & 590.1 & 520.0 & 480.5 & 460.1 \\
\hline Reduction & & 526.1 & 37.2 & 60.0 & 70.1 & 39.5 & 20.4 \\
\hline $\begin{array}{l}\text { Degrees of } \\
\text { freedom }\end{array}$ & & 9 & 1 & 2 & 2 & 1 & 1 \\
\hline $\mathrm{p}$-value & & .001 & .001 & .001 & .001 & .001 & .001 \\
\hline
\end{tabular}

N.S.S. $=$ No statistically significant effect at level .05.

The following observations arise from this table. In model 1 the variables related to the student context were added to the empty model (model o). This model explained $23.4 \%$ of the variance, most of which was attributed at the student level. The $\chi^{2}$ test revealed a significant change between the baseline model and model 1 ( $\mathrm{p}<0.001)$. Second, all student context variables (i.e., prior achievement in maths, gender, SES, Cultural capital) had statistically significant effects on student achievement. Boys were found to have better results than the girls. Nevertheless, prior knowledge had the strongest effect in predicting student achievement at the end of the school year. In addition, prior achievement is the only contextual variable that had a consistent effect on achievement when aggregated either at the classroom or the school level.

In model 2, the explanatory variables of the student level related to the opportunity to learn were added to model 1. The amount of time 
students spent on doing their homework had a statistically significant effect on student achievement. In the third model, all variables related to teacher background factors and teacher perceptions and attitudes were added to model 2. "Teacher years of experience" has a statistically significant effect on student achievement, whereas "teacher positive attitudes towards dealing with administrative work" has a negative effect on student outcomes. This model explained $30.2 \%$ of the variance and the $\chi^{2}$ test revealed a significant change between model 2 and model 3 $(\mathrm{p}<0.001)$.

In the next model (i.e., model 4 ), the variable related to the quality of teaching was added to model 3. Quality of teaching was measured through classroom observations and teachers were assigned to four developmental stages according to their teaching skills. In order to measure the effect of each developmental stage on student outcomes, teachers at stage 3 were treated as a reference group (i.e., stage $3=0$ ) and three dummy variables were entered in model 4 . The results revealed that the developmental stage at which a teacher is situated has a considerably large and statistically significant effect on student achievement. Specifically, we can observe that the students of teachers at stage 1 have the lowest achievement, whereas students of teachers at level 4 have higher achievement than students of the first three levels. This finding provides support to the developmental nature of the four stages, since students of teachers who were found to belong to higher levels performed better than students of teachers at lower levels. Finally we can observe that model 4 explained $35.8 \%$ of the variance while the $\chi^{2}$ test revealed a significant change between model 3 and model 4 ( $\mathrm{p}<0.001)$, which implies that a teacher's developmental stage is an important predictor of student outcome measures.

In model 5, the effect of each approach employed on teacher professional development was investigated. A dummy variable indicating the approach employed ( $\mathrm{o}=\mathrm{HA}$ ) was entered into the analysis. The DIA was found to have a statistically significant effect on student achievement compared with the HA. Specifically, the effect of this variable is 0.24 (0.08), indicating that the students of teachers employing this approach have better results in their achievement than those whose teachers employed the Holistic Approach. In addition, we can observe that model 5 explained $38.5 \%$ of the variance while the $\chi^{2}$ test revealed a significant change between model 4 and model $5(\mathrm{p}<0.001)$. This provides further support to the argument that the approach used 
in teacher professional development programmes is an important predictor of student outcome measures.

Finally, in model 6 the effect of teachers moving to the next developmental stage was investigated. As mentioned in the analysis of the observational data related to the quality of teaching, overall all teachers employing the DIA managed to improve their teaching skills. Moreover, 21 of them made progress to an extent that allowed them to move to the next developmental stage of teaching skills. Thus it was necessary to investigate the impact of this "movement" to the next developmental stage on student academic outcomes. A dummy variable indicating whether teachers managed to move to the next developmental stage was entered in the analysis ( $\mathrm{o}=$ no movement observed, $1=$ moving to the next stage of teaching competences). According to the results in the last column of the above table, moving to the next developmental stage was found to have a statistically significant effect on student achievement.

\section{Discussion}

The findings of this study support the hypothesis that teachers can improve and ultimately progress to the next developmental stage of teaching skills, providing they undergo appropriate treatments and participate in effective professional development programmes. As this study has demonstrated, teachers employing the DIA managed to improve their teaching skills, whereas those employing the HA did not manage to do so. In addition, the use of the DIA had a significant impact on student achievement gains in mathematics. A similar observation was made by King and Kitchener (1994), who argued that stage growth is most apparent in teachers who continue their informal education and participate in effective professional development programmes. This is an important reminder that teacher improvement and stage growth does not unilaterally unfold but requires a stimulating and supportive environment.

The issue related to the content of teacher professional development programmes has been addressed in this study by drawing from a validated theoretical model of EER. Specifically, in attempting to describe the complex nature of effectiveness, the dynamic model of educational effectiveness points out not only the importance of specific factors but also searches for grouping of factors. This implies that improvement of teacher effectiveness can be focused neither solely on 
the acquisition of isolated skills/competencies (Gilberts \& LignugarisKraft, 1997) nor on reflection across the whole process of teaching in order to help teachers to achieve "greater fulfilment as a practitioner of the art" (of teaching) (Clarke \& Hollingsworth, 2002, p. 948).

At the same time, the results of this study indicate that reflection is more effective when the improvement priorities of teachers are taken into account and teachers are encouraged to develop action plans that address their professional needs, as has been identified through relevant empirical investigation. Although both experimental treatments encouraged and utilised critical reflection of teachers on their teaching practices, teachers employing the DIA were asked to reflect on those aspects of their teaching practice that were found to be related to their priorities for improvement based on the stage on which they were situated. These stages were defined by taking into account the knowledgebase of EER and especially teacher factors found to be associated with student achievement (Kyriakides et al., 2009).

On the other hand, teachers employing the holistic approach adopted a less focused reflection strategy, which allows teachers to reflect on any aspect of their teaching practice irrespective of the stage on which they were situated. For example, some teachers situated at level 1 employing the holistic approach developed action plans aiming to differentiate their instruction, but their attempts to incorporate differentiation in their teaching were not successful at all. This can be attributed to the fact that they did not possess basic skills corresponding to their stage, such as classroom management and structuring, which could be considered to be a prerequisite for the differentiation of teaching. Thus the holistic approach does not take into account research evidence suggesting that teacher factors and their dimensions can be grouped into stages, structured in a developmental order and associated with student outcomes. This is not to deny in any way that thinking and critical analysis are important, and for this reason these aspects of the holistic approach have been utilised in the development of the DIA. However, complementing reflection with the knowledgebase of EER, which addresses the need for specific groups of teachers, could help us establish more effective approaches to teacher professional development.

The empirical justification of the notion of developmental stages of teaching skills has important policy implications. In particular, policy development could be directed to the establishment of different training courses to address the needs of specific groups of teachers, 
according to their developmental stage. The findings of the experimental study provide further support for the fact that improvement of skills and professional development take place gradually. Although the study took place for only one school year, its findings seem to reveal that teachers should master simple but necessary routines such as teaching skills related to the direct teaching approach (i.e., stages 1 and 2) in order to move to the higher stages involving the use of "new learning" approaches and differentiation (i.e., stages 4 and 5). A similar argument has been made by Berliner (1992), who suggests that it is a fallacy to assume that the methods of the experts either can or should be taught directly to beginners. However, all of the stages are of fundamental importance to the professional development of teachers, and educators must be capable of intervening in all stages.

It is important to clarify that in the integrated approach to teacher professional development described in this paper an important aim is to facilitate the process whereby the inner levels of theoretical knowledge of research findings on teacher effectiveness influence the outer levels of teaching practice. In other words, what matters is developing effective teaching behaviour, and to that end it is vital that teachers are not only cognitively aware of the theoretical knowledge related to each factor but that they take the step leading to conscious decisions to make use of this knowledge, and then carry out those decisions effectively. This procedure is significant since many models for reflection are in fact phase models describing the reflection process, and make no pronouncements on the question of what teachers can reflect on. In this sense, the evaluation results, based on the dynamic model, can supplement the process of reflection by helping teachers to determine the skills on which they need to concentrate their efforts for improvement.

Moreover, the findings of this study reveal that teacher perceptions of teaching were not modified for the teachers employing either the DIA or the HA. This finding is in line with many studies that suggest that changing teacher perceptions is hard to achieve (Goodrum, Cousins \& Kinnear, 1992; Joyce \& Showers, 1980; Sharon, 1987). For example, in research done in the USA by Alger (2009) in a district that offers "a myriad of choices of professional development from workshops on particular strategies to development of small learning communities" (p. 8), it was surprising to note that only one teacher (out of 110) indicated that professional development was responsible for a shift in his or her perceptions of teaching. As research has shown, teacher beliefs about teaching and learning are resistant to change because they 
are at the core of a student teacher's world view (Pajares, 1992; Phelan \& McLaughlin, 1995). An alternative explanation may be that teacher perceptions may be mitigated by other less tangible context variables in individual schools, such as school size and school climate (Grossman and Stodolsky, 1995). In addition, this might be attributed to the fact that the study took place for one year only. Longitudinal studies are needed to further explore the potential and the characteristics of professional development programmes capable of improving teacher perceptions of teaching.

Nevertheless, despite the fact that teacher perceptions of teaching were not modified in this study, those teachers employing the DIA did manage to improve their teaching skills and their student outcomes. This might imply that improving teacher perceptions and attitudes towards teaching should not necessarily be considered as a prerequisite for improving teacher effectiveness, especially when teachers have volunteered to participate in professional development programmes. This, however, might not be the case when compulsory professional development programmes are imposed on teachers. Further research is needed to clarify this issue.

Finally, suggestions for further research aimed at establishing closer links of EER with teacher professional development are provided. Longitudinal studies may help us to measure both the short term and the long term effect of the DIA. Further studies are also needed in order to test the generalisability of the findings of the study reported here and to expand the proposed theoretical framework. Such studies may reveal that in helping teachers improve their skills other factors such as school policy regarding teaching and school culture should be considered. Such results may not only contribute to the further development of the framework related to the use of the dynamic model for improvement purposes but may also help us establish a theory-driven and evidence-based approach to improving the quality of education.

\section{References}

Alger, C. (2009). Secondary teachers' conceptual metaphors of teaching and learning: Changes over the career span. Teaching and Teacher Education, 25(5), 743 - 751.

Antoniou, P. (2009). Using the Dynamic Model of Educational Effectiveness to Improve Teaching Practice: Building an Evaluation Model to Test the Impact of Teacher Professional Development Programs. Unpublished Doctoral Dissertation, University of Cyprus, Cyprus. Berliner, D. (1992). Expertise in teaching. In F. Oser, J. - L.Patry \& A. Dick (Eds.), Effective and responsible teaching (pp. 227-249). San Francisco: Jossey-Bass. 
Bond, T., \& Fox, C. (2001). Applying the Rasch Model: Fundamental Measurement in the Human Sciences. Mahwah NJ: Lawrence Erlbaum Associates. (Available from IOM.).

Borko, H. (2004). Professional development and teacher learning: Mapping the terrain. Educational Researcher, 33(8), 3-15.

Byrne, B. (1998). Structural equation modeling with LISREL, PRELIS, and SIMPLIS: Basic concepts, applications and programming. Mahwah, NJ: Erlbaum.

Calderhead, T. (1989). Reflective teaching and teacher education. Teaching and Teacher Education, 5(1), 43-51.

Chandler, P., Robinson, W.P., \& Noyes, P. (1991). Is a Proactive Student Teacher a Better Student Teacher? Research in Education, 45(May), 41-52.

Clarke, D., \& Hollingsworth, H. (2002). Elaborating a model of teacher professional growth. Teaching and Teacher Education, 18(8), 947-967.

Cochran-Smyth, M., \& Zeichner, K. (2005). Studying teacher education. The report of the AERA panel on research and teacher education. USA: American Education Research

Association.

Cohen, D.K. (1990). A revolution in one classroom: The case of Mrs. Oublier. Educational Evaluation and Policy Analysis, 12(3), 311-329.

Cornford, I. R. (2002). Reflective teaching: empirical research findings and some implications for teacher education. Journal of Vocational Education and Training, 54(2), 219-235.

Creemers, B. P. M., \& Reezigt, G. J. (1997). School effectiveness and school improvement: Sustaining links. School Effectiveness and School Improvement, 8(4), 396 - 429.

Creemers, B. P. M., \& Kyriakides, L. (2006). A critical analysis of the current approaches to modelling educational effectiveness: the importance of establishing a dynamic model. School Effectiveness and School Improvement, 17(3), 347-366.

Creemers, B. P. M., \& Kyriakides, L. (2008). The Dynamics of Educational Effectiveness: A Contribution to Policy, Practice and Theory in Contemporary Schools. London: Routledge. Creemers, B. P. M., Kyriakides, L., \& Antoniou, P. (Eds.) (in press). A Dynamic Approach to Teacher Training and Professional Development. New York, USA: Springer Publishing. Day, C. (1999). Developing Teachers: the challenges of lifelong learning. London: Falmer Press.

Desimone, M.L., Porter, C.A., Garet, S.M., Yoon, S.K., \& Birman, F.B. (2002). Effects of professional development on teachers' instruction: Results from a three-year longitudinal study. Educational Evaluation and Policy Analysis, 24(2), 81-112.

Elliot, J. (2002, August). Action research as the basis of a new professionalism for teachers in an age of globalisation. Paper presented at a conference to celebrate the centenary year of Beijing Normal University, Beijing, China.

Gilberts, G. H., \& Lignugaris-Kraft, B. (1997). Classroom management and instruction competencies for preparing elementary and special education teachers. Teaching and Teacher Education, 13(6), 597-610. 
Golby, M., \& Viant, R., (2007). Means and ends in professional development. Teacher

Development, 11(2), $237-243$.

Goodrum, D., Cousins, J., \& Kinnear, P. J. (1992). The reluctant primary school teacher.

Research in Science Education, 22(2), 163-169.

Grossman, P. L., \& Stodolsky, S. S. (1995). Content as contest: the role of school subjects in secondary school teaching. Educational Researcher, 24(8), 5-11.

Guskey, T. R., \& Sparks, D (2004). Linking professional development to improvements in student learning. In E. M. Guyton \& J. R. Dangel (Eds.), Teacher Education Yearbook XII: Research Linking Teacher Preparation and Student Performance. Dubuque, IA: Kendall/ Hunt.

Hatton, N., \& Smith, D. (1995). Reflection in teacher education: Towards definition and implementation. Teaching and Teacher Education, 11(1), 33-49.

Joyce, B.R., \& Showers, B. (1980). Improving inservice training: The messages of research. Educational Leadership, 37(5), 379-385.

King, P. M., \& Kitchener, K. S. (1994). Developing reflective judgment: Understanding and promoting intellectual growth and critical thinking in adolescents and adults. San Francisco: Jossey-Bass.

Kyriakides, L., \& Creemers, B. P. M. (2008). Using a multidimensional approach to measure the impact of classroom-level factors upon student achievement: a study testing the validity of the dynamic model. School Effectiveness and School Improvement, 19(2), $183-205$.

Kyriakides, L., Creemers, B. P. M., \& Antoniou, P. (2009). Teacher behaviour and student outcomes: Suggestions for research on teacher training and professional development. Teaching and Teacher Education, 25(1), 12-23.

Marcoulides, G. A., \& Drezner, Z. (1999). A procedure for detecting pattern clustering in measurement designs. In M. Wilson \& G. Engelhard, Jr. (Eds.), Objective measurement: Theory into practice (Vol. 5). Westport, Conn.: Ablex Publishing Corporation.

McNamara, D. (1990). Research on Teachers' Thinking: its contribution to educating student teachers to think critically. Journal of Education for Teaching, 16(2).

Ministry of Education (1994). The New Curriculum. Nicosia: Ministry of Education. Pajares, M. F. (1992). Teachers' beliefs and educational research: cleaning up a messy concept. Review of Educational Research, 62(2), 307-332.

Phelan, A. M., \& McLaughlin, H. J. (1995). Educational discourses, the nature of the child, and the practice of new teachers. Journal of Teacher Education, 46(3), 165-174.

Reynolds, D., Hopkins, D., \& Stoll, L. (1993). Linking school effectiveness knowledge and school improvement practice: Towards a synergy. School Effectiveness and School Improvement, 4(1), 37-58.

Schon, D. A. (1983). The reflective practitioner: How professionals think in action. New York: Basic Books.

Sharon, D. (1987). The Renfrew Quality Education Project: Teachers' views after the first 
year. Working Papers of the Planning and Development Research Branch, TV Ontario, $87(2)$.

Snijders, T., \& Bosker, R. (1999). Multilevel Analysis: An Introduction to Basic and Advanced Multilevel Modeling. London: Sage.

Stoiber, K. (1991) The Effect of Technical and Reflective Instruction on Pedagogical Reasoning and Problem Solving. Journal of Teacher Education, 42(2), 131-139.

Tom, A. (1985). Inquiring into inquiry-oriented teacher education. Journal of Teacher

Education, 36(5), 35-44.

U. S. Department of Education, National Center for Education Statistics. (1999). Teacher quality: A report on the preparation and qualifications of public school teachers (NCES 1999o8o). Washington, DC: Author.

Van Manen, M. (2002). The pathic principle of pedagogical language. Teaching and Teacher Education, 18(2), 215-224.

Winitzky, N., \& Arends, R. (1991), 'Translating Research into Practice: The Effects of Various Forms of Training and Clinical Experience on Preservice Students' Knowledge, Skill and Reflectiveness'. Journal of Teacher Education, 42(1), 52-65.

Wubbels, Th., \& Korthagen, F. (1990). The effects of preservice teacher education program for the preparation of reflective teachers. Journal of Education for Teaching, 16(1), 29-43.

Zeichner, K.M. (1987). Preparing reflective teachers: An overview of instructional strategies which have been employed in preservice teacher education. International Journal of Educational Research, 11(5), 565-575. 
Appendix 1. Results of comparing teachers of the two experimental groups based on their initial and final perceptions and attitudes

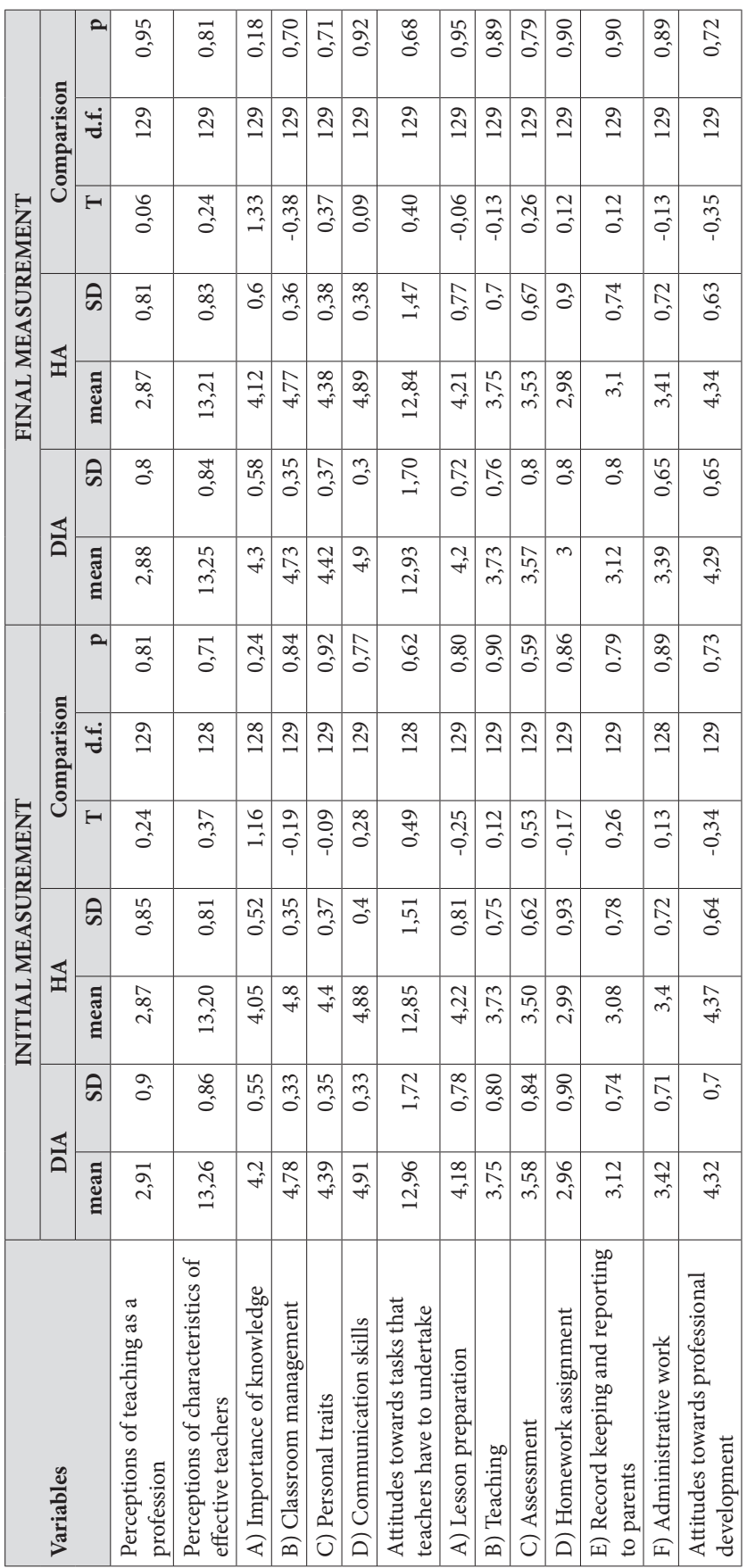




\section{Biographical note}

Panayiotis Antoniou is Assistant Professor of Educational Leadership and Evaluation and the Director of the MSc in Educational Leadership at the Cyprus International Institute of Management. His research interests are related with teacher training and professional development, instructional leadership and school effectiveness and school improvement. He has participated in various research projects related with the improvement of education and the development of a new national evaluation system for teachers and schools in Cyprus. He has presented his work in international conferences and has published in various international scientific journals and books.

LeONidAs Kyriakides is Associate Professor in Educational Research and Evaluation at the University of Cyprus. His research interests are modeling educational effectiveness, research methods in educational effectiveness, and the application of effectiveness research to the improvement of educational practice. He is involved as researcher and advisor in the development of the national reform policy on teacher professional development in Cyprus. He is also a member of the editorial board of various international journals and the book review editor of the School Effectiveness and School Improvement journal. He is the author of more than 80 research papers in international journals, 5 books and 40 chapters in books.

Bert P. M. Creemers is currently Honorary Professor in Educational Sciences especially Educational Effectiveness at the University of Groningen., the Netherlands. He is founding and corresponding editor of School Effectiveness and School Improvement and of Educational Research and Evaluation Journals. Further, he is a member of the editorial board of other scientific and professional journals. He is involved as a researcher and/or as an advisor in the development and the evaluation of education in the Netherlands and in many other countries. His main interests are research and evaluation in teaching, educational effectiveness and improvement. 